\title{
PRÁTICAS DE GESTÃO EM TRANSPORTES COLETIVOS URBANOS POR ÔNIBUS: CASO DE EMPRESAS NO RIO DE JANEIRO
}

\author{
H.C.A.G.Afonso ${ }^{1}$; M.P.S.Santos ${ }^{1}$ \\ 1 Universidade Federal do Rio de Janeiro, 21941-450, Rio de Janeiro-RJ, Brasil \\ *herc_afonso@hotmail.com
}

Artigo submetido em 01/2014 e aceito em 01/2015

\section{RESUMO}

Este artigo trata das práticas de gestão das empresas de transporte coletivo por ônibus do Rio de Janeiro. Fez-se um levantamento bibliográfico e estudo de casos, por meio de entrevistas aos administradores de algumas destas empresas. Constatou-se que, apesar de algumas resistências às mudanças e equívocos quanto às práxis, as empresas têm adotado práticas de gestão diversificadas para se manterem no mercado ante a concorrência, com destaque para tecnologias e o empowerment tímido, mas ainda não possuem mecanismos claros de avaliação de seu próprio desempenho.

PALAVRAS-CHAVE: Transporte coletivo, ônibus, gestão das organizações.

\section{MANAGEMENT PRACTICES IN COLLECTIVE URBAN TRANSPORT BUS: CASES IN RIO DE JANEIRO}

\begin{abstract}
This article discusses the practices of corporate management of collective transport by bus from Rio de Janeiro. It was made a bibliographical survey and study of cases through interviews with managers of some of these companies. As results, it found that, despite some resistance to the changes and mistakes about praxis, the
\end{abstract}

companies have adopted management practices diversified to remain itself in the market before the competition, and emphasis on technologies and empowerment shy, but not yet clear mechanisms for evaluation their own performance.

KEYWORDS: collective transport, bus, organizational management. 


\section{INTRODUÇÃO}

A partir do final da década de 1980, o Brasil avançou bastante em termos do processo de transformação e reestruturação produtiva, organizacional e urbana, com impacto direto para a mobilidade e a qualidade de vida dos cidadãos (Leite, 1996). Tais transformações decorreram de importantes inovações tecnológicas havidas e que impactaram na dinâmica socioeconômica e ambiental, institucional, por meio da re-definição do papel do estado, cada vez mais regulador que produtor. Aceleraram-se a flexibilidade do mercado de trabalho - p.e. o tele-trabalho; diversas formas de poluição, como a taxa de motorização, o congestionamento entre outros fatores que afetam a mobilidade urbana.

No Brasil, quase a totalidade do sistema de transporte coletivo por ônibus é explorado por empresas privadas. Com o passar dos anos, parte destas empresas passou por processo de modernização gerencial, implantando de forma sistemática modelos de gestão empresarial (Orrico Filho, et al. 1996), compatíveis com o atual ambiente competitivo no qual se insere. Não obstante, recentemente, diversos estudos vêm indicando a perda de passageiros por parte das empresas de ônibus, principalmente a partir do final da década de 1990. Esse fenômeno deveu-se ao aumento da participação de Veículos de Pequeno Porte - VPP no movimento de pessoas (Ferreira, 2006), sendo que parte destes VPP é devidamente regulamentado e a outra parte funciona de forma irregular ou clandestina. Esse tipo de transporte concorre com certa vantagem com o sistema regular - ônibus. A nova forma de prestação de serviço de transportes possui uma modelo organizacional e gerencial bem estruturado e modernizado, razão pela qual consegue subtrair parcelas cada vez maiores de passageiros do sistema regular.

Com efeito, os desafios da concorrência entre empresas de transportes regulares e o de permanecer no mercado para atender as disposições contratuais junto ao poder público impõem às empresas de ônibus um "re-inventar" em suas práticas de gestão. Portanto, o objetivo central desse artigo consiste analisar as principais práticas de gestão implementadas por algumas empresas de ônibus do Estado do Rio de Janeiro.

\section{REVISÃO DA LITERATURA}

\subsection{Gestão das organizações e suas práticas}

Esforços científicos têm sido dedicados por especialistas de várias áreas no mundo inteiro no intuito de estudar as transformações, processos e formas de gestão em meio a um ambiente de competição altamente volátil, por ocasião da globalização e a nova economia - economia da informação, entre os quais se destacam Bauer (1999), Bauman (1999), Drucker (2002), Porter (1999), Prahalad \& Ramaswamy (2004). Predominantemente, manifestam preocupação com o futuro das organizações, estrutura de mercados, clientes e práticas de gestão que potencialize a visão holística e empowerment etc..

As práticas de gestão das organizações remontam os primórdios do próprio processo da organização da atividade econômica; e foram evoluindo até aos nossos dias, adotando estratégias multiformes de acordo com a complexidade da empresa e do seu grau de inserção no mercado global (Telles, 2003; Cardoso, et al. 2005).

Segundo Cecconello \& Ajzental (2008), o organograma de uma empresa pode revelar aspectos sobre sua cultura, a forma estruturada de seus processos operacionais, além de disfunções organizacionais decorrentes, seja em função da evolução de atividades operacionais sem as devidas readequações, seja por acomodações de interesses pessoais, discutíveis, quanto ao que seria melhor para a empresa. A opção por um modelo de gestão por parte de uma empresa influencia a postura e 
a atitude organizacional, mostrando-se mais ou menos adequado à operação e ao contexto de atuação.

Entre as décadas de 1960/70, o mundo ocidental "resgatou da antiguidade grega" o modelo de gestão participativa como forma de elevar a produtividade das empresas de países da Europa ocidental superarem a dos EUA, embora este último tivesse maior plataforma de desenvolvimento tecnológico. Com efeito, a administração participativa despontou e se consolidou como um dos fatores diferenciadores de produtividade e contribuiu para o extraordinário avanço tecnológico dos produtos fabricados em países orientais (Ferreira et al., 1997). No contexto da produtividade e eficiência, a participação é instrumentalizada como tecnologia social à disposição da gerência e destinada a assegurar maior produtividade e eficiência. $O$ fato é que este modelo de gestão almejara alcançar objetivos genéricos tais como: responsabilidades sociais da empresa; equilíbrio dos interesses dos vários envolvidos; cultura democrática; redução da alienação; utilização de todo o potencial das pessoas; diminuição de conflitos através da cooperação; satisfação das pessoas; maior competitividade (autor, op. cit.).

O conjunto destes objetivos remeteria ao holismo, que ultimamente tem sido a "jargão" comum no processo de gestão de empresas, como forma de enfrentamento das plasticidades e flexibilidades das organizações competitivas, devidamente inseridas na economia global. A empresa não é mais vista como um conjunto de departamentos, que executam atividades isoladas, mas como um corpo uno, um sistema aberto e em contínua interação como o ambiente. Cabe destacar, entretanto, que a implementação do processo da administração holística pressupõe o profundo conhecimento do(a): definição das políticas da empresa; reconhecimento dos valores da empresa - a visão, missão e valores relevantes; diagnóstico da empresa ou a avaliação do patrimônio social da empresa - recursos humanos, tecnologia, fornecedores, clientes, sistemas de distribuição, produtos, marca, imagem, análise d clima e da cultura da organização; identificação do núcleo da empresa, ou seja, o mapeamento dos pontos fortes, suas competências em seu negócio; análise do meio externo para perceber a situação político-econômico-cultural, tecnológica, concorrência e suas relações com a empresa.

Nos anos 80, as grandes empresas cresceram de forma desordenada através da diversificação para novos negócios. Criaram estruturas gigantescas para competir numa era em que a velocidade e a flexibilidade são os dois requisitos-chave. Muitas vezes, para enfrentar os desafios da competitividade global, as empresas adotam estratégias espúrias (Procknick, 1991, Viotti, 2005). Nos anos 90, dá-se a emergência do downsizing, um modelo de gestão, que implica a redução radical do tamanho da empresa, por meio de redução dos níveis hierárquicos - delayering - ou da venda de negócios não estratégicos. As empresas ganham flexibilidade, perdem burocracia e ficam mais próximas do mercado e dos clientes. Na prática, downsizing envolve análise dos custos, evolução de indicadores, avaliação do valor agregado ao produto e não somente corte indiscriminado da força de trabalho para enxugamento. Outros fatores como a promoção da sinergia entre os membros da empresa, comunicação eficiente e menos distorcida e a rapidez nas tomadas de decisões também podem ser motivos para que seja feito um downsizing (Costa et al., 2007).

No Brasil, é comum a utilizar-se o termo prática de gestão para representar um conjunto de atividades de natureza gerencial, sistematizadas por meio de métodos e regras de execução, formalizadas ou não, e que compõem o modelo de gestão da organização.

Em transportes, as transformações do transporte público urbano é um resultado da dinâmica dos tempos atuais. Os usuários se tornam cada vez mais exigentes e as empresas operadoras 
necessitam adaptar-se os novos modelos de gestão em busca da satisfação das "novas" demandas de transporte (Malavé e Bodmer, 1998.).

\subsection{Organização da Produção de Transportes por Ônibus}

A organização do trabalho nas empresas de transporte coletivo por ônibus se dá em dois loci: na garagem e na linha. Na garagem, o setor administrativo cuida do suporte necessário à atuação da manutenção e operação. A manutenção providencia os veículos, que devem estar em perfeito estado para sua utilização nas linhas e na produção do serviço de transporte. O serviço da linha é realizado pela equipe de operação, compreendendo o motorista, cobrador, despachante, fiscal e inspetor. A organização do trabalho se dá a partir do despachante, que tem a função de controlar e registrar o fluxo de veículos, a movimentação de pessoal de operação, dando suporte à garagem sobre quaisquer alterações significativas no serviço. Cada linha de ônibus tem suas peculiaridades pelos horários, itinerários, tipo de veículo e esquema de folga, mas também advindas da configuração rede, grupo socioeconômico e cultural de passageiros, características urbanas, passageiros por trecho e viagem, a condição de tráfego nas vias etc.

\subsection{Marketing em transporte coletivo por ônibus}

Marketing é a parte do processo de produção e de troca relacionada com o fluxo de bens e serviços do produtor ao consumidor. Enquanto função organizacional, segundo American Marketing Association - AMA (2008), marketing é a atividade, jogo de instituições e processos de criação, comunicação, entrega e troca de ofertas que têm valor para os clientes, clientes, parceiros e sociedade em geral. Para Kotler e Keller (2006), marketing é um processo social por meio do qual, pessoas e grupos de pessoas obtêm aquilo de que necessitam e o que desejam com a criação, oferta e livre negociação de produtos e serviços.

O mix de marketing, quando aplicado aos transportes públicos, figura 1, é composto por: Ponto, que significa o acesso ao serviço; O Preço, como um diferencial competitivo, desde que não prejudique a qualidade dos produtos e serviços, ou o nível de lucratividade da empresa (Souza et al., 2013). A Praça, pré-estabelecida por força de regulamentação - licitação pública, fixando os itinerários e horários, ou mesmo área geográfica; As Pessoas, como elemento determinante para as atividades de marketing externo, interativo e interno; exercendo algum papel na execução do serviço, seja de gerencia, seja de apoio, tais como, motoristas, cobradores, fiscais, despachantes, inspetores, bilheteiros, telefonistas, mecânicos, supervisores, arrecadadores; sendo que, o grau de respostas às expectativas dos clientes determina de certa forma o grau de flexibilidade da empresa e o seu poder de venda (Souza et al., 2013). As evidências físicas ou tudo que faz parte do ambiente de serviço, as instalações e equipamentos, uniformes dos funcionários, as condições de higiene e limpeza interna e externa dos ônibus, tecnologia de transporte, o layout das facilidades e acesso, como forma de melhor atendimento aos usuários e também seus quadro de pessoal; O Processo, caracterizado pelas condições estabelecidas e para a realização das viagens, é um indicador utilizado pelo cliente para balizar a qualidade do serviço prestado; A Promoção trata da comunicação do serviço ao mercado, focado para o usuário, tais como: anúncios, publicidade, busdoor, panfletos sobre horários e tipos de serviços, promoções em "horários entre-picos". Uma das formas que as empresas de ônibus têm apostado para estimular a utilização do transporte coletivo é a concessão de descontos tarifários. São $24 \%$ das operadoras, aproximadamente, que promoveram descontos nas tarifas em todos os dias e horários (NTU, 2007). 


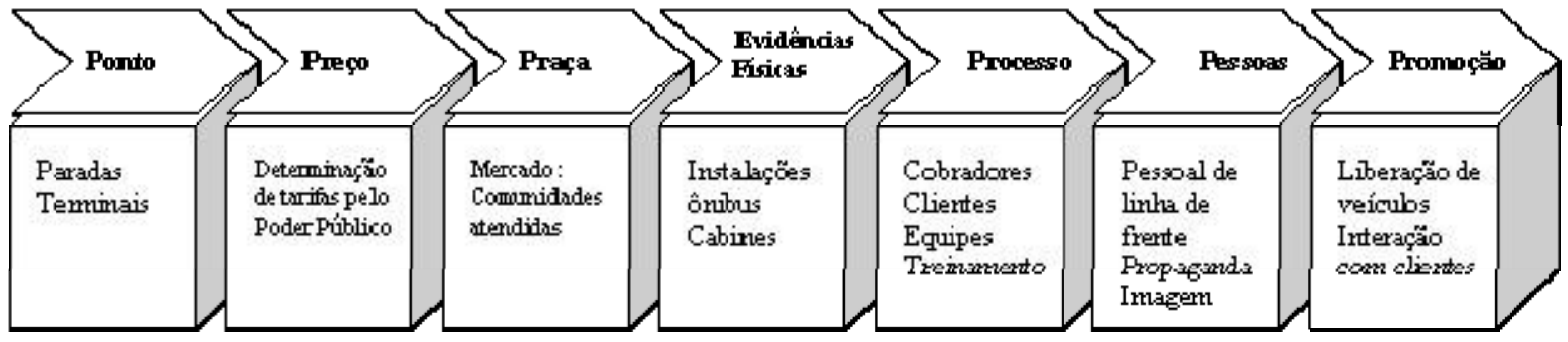

Figura 1 - $O$ composto de marketing expandido para serviços.

Fonte: Adaptado de Zeithaml et al (2003)

\subsection{Clientes e serviços de transportes}

Clientes são "bens" produzidos pelos transportes. Trata-se de bens do tipo diferenciado e especial, não passivos e com peculiaridades únicas, pois são capazes de emitir juízos de valor na avaliação de benefício-custo, no desempenho, além de influenciar em todos os processos administrativos e de gestão de empresas de transportes. Clientes habituais e cativos têm uma representatividade constante no resultado financeiro da empresa.

Em transportes, uma das estratégias é traçar o perfil dos consumidores de viagens e consumidores dos serviços concorrentes, a fim de se avaliar os padrões de seus deslocamentos, e assim construir estratégias para a inserção destes na carteira de clientes das transportadoras. Segundo Silva (2004), os serviços apresentam três características básicas: intangibilidade, heterogeneidade e inseparabilidade. No que concerne às empresas de ônibus, a implementação de práticas organizacionais modernas e competitivas estão vinculadas às características do produto, em termos de produção e consumo, processos etc., conforme resumo apresentado no quadro 1

Quadro 1- Diferenciação de produtos de transporte coletivo por ônibus

\begin{tabular}{|c|c|}
\hline Itens & Peculiaridades do setor de transportes coletivos \\
\hline Estoques & Não estocabilidade \\
\hline Produção & Derivativa; onde e quando necessário \\
\hline Meio de Produção & Fora da fábrica; Infraestrutura viária e capacidade limitada (na linha e/ou rede o/d). \\
\hline Dispersão/concentração & Pequenas unidades espalhadas pela cidade \\
\hline Relação espaço-tempo & Tempo e espaço integram o produto; \\
\hline Produto & $\begin{array}{l}\text { Duas linhas ou horários diferentes; diferentes produtos; multiplicidade de produtos } \\
\text { de TPU (seletivo, expressos, parador, fretado, condomínio). Linha ou rede. }\end{array}$ \\
\hline Tecnologia & Similaridade tecnológica \\
\hline Oferta & Padronização por parte do produto oferecido por diversas empresas \\
\hline Linhas & Agrupamento da multiplicidade em sub-mercado, especialmente sobrepostos \\
\hline Empresa & Indústria multi-produto \\
\hline Mobilidade-acessibilidade & Limitada e cartesiano (bidimensional) \\
\hline Eficácia (elementos exógenos) & $\begin{array}{l}\text { Relativa. Deslocamento físico sujeito a congestionamento por motivos diversos, } \\
\text { que afeta a relação custo/tempo de viagem }\end{array}$ \\
\hline Substitubilidade & Alta: transportes alternativos (regulares ou não) \\
\hline
\end{tabular}

Fonte: (1) Orrico Filho et al (1996); (2) Elaborada pelo autor. 


\section{MATERIAIS E MÉTODOS}

Metodologicamente, a pesquisa é bibliográfico-documental e de estudo de caso, a fim de se verificar a práxis entre a teoria e a prática das organizações. Foram vasculhados livros de administração empresarial - impressos e na forma virtual, as abordagens sobre as práticas de gestão adotadas pelas organizações, seus elementos e fatores que nortearam a sua evolução até aos dias atuais. Nessa etapa, privilegiaram-se as técnicas de pesquisas bibliográficas e argumentativa, como escopo teórico. Caracterizou-se o sistema de transporte coletivo por ônibus que operam linhas no Estado do Rio de Janeiro, as forças concorrenciais recentes e o modo como estas empresas vêm se organizando para permanecerem no mercado.

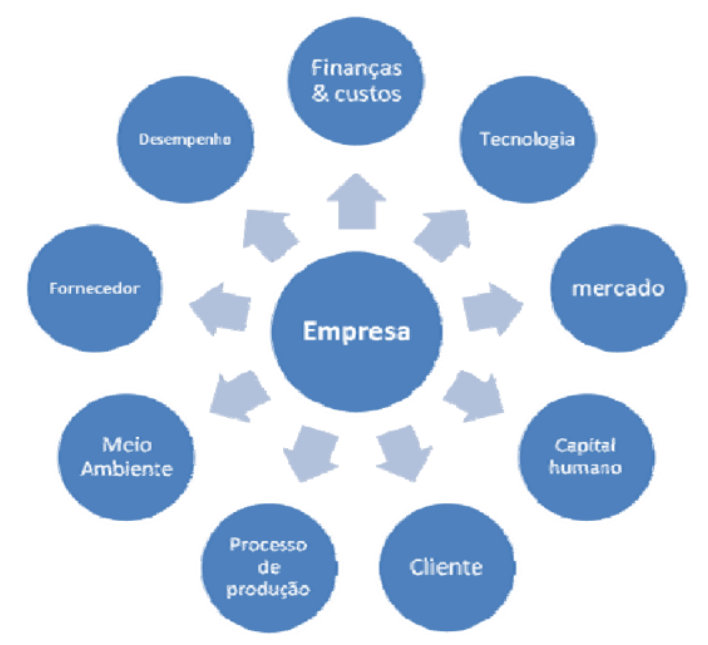

Figura 2 - Elementos de análises das organizações

Nesse sentido, têm adotados modelos ou práticas de gestão para assegurar tanto a sobrevivência no mercado sob forte concorrência de alternativos, como também o diagnóstico de oportunidades de expansão em certos nichos de mercado. Diante do estudo preliminar, houve a necessidade de se desenvolver e aplicar questionários formulados a algumas empresas do setor.

O critério de seleção das empresas foi com base do conhecimento que se tem sobre sua representatividade em termos de grupos (controlados) e da região de atuação. Os formulários foram encaminhado pela Fetranspor à empresas previamente selecionadas, devendo ser respondido pelo gerente ou proprietário das mesmas, e foram estruturados conforme o seguinte esquema da Figura 2. Os nove blocos permitem situar a empresa quanto a seu posicionamento diante de aspectos fundamentais de planejamento estratégico e das práticas de gestão. No questionário, usou-se a técnica hibrida, ao se conjugar elementos qualitativo e quantitativo, este último, por meio de atribuição de valor na escala de 0 à 10 . O objetivo consiste em quantificar o grau de importância atribuída a cada assunto dentro de um determinado bloco. O trabalho em questão, entretanto, apenas pode sinalizar as "forças" que norteiam as práticas de gestão e suscitar interesses quanto ao seu aprofundamento no futuro, em função do tamanho da amostra, restrição de tempo. 


\section{RESULTADOS E DISCUSSÃO}

\subsection{Sistema de transporte coletivo urbano por ônibus}

O transporte coletivo de passageiros é um serviço público essencial e desenvolve um papel social e econômico de grande importância. Trata-se de um sistema que apresenta grande potencial de democratizar ou não a mobilidade, reduzir congestionamentos e diversos níveis de poluição e o uso indiscriminado de energia automotiva, além de minimizar a necessidade de construção de vias e estacionamentos. Com efeito, na acepção de Henry \& Zioni (2003), o ônibus privado aparece como produto e condição da metropolização, na medida em que a conurbação incorpora numerosos municípios periféricos, a semelhança "postura" urbanizadora já exercida pela Light, guardadas devidas peculiaridades quanto a forma exploração/concessão do serviço.

De acordo com a pesquisa da NTU (2009), diariamente são realizados 200 milhões de deslocamentos motorizados nas cidades brasileiras. Esses deslocamentos acarretam enormes custos de tempo, de poluição, de acidentes e de investimento; e prejudicam a mobilidade da população. Este problema tende a se agravar, com reflexos negativos na produtividade, no meio ambiente urbano e na qualidade de vida. A julgar pelas transformações ocorridas no Brasil nas últimas duas décadas, constata-se que perfil dos deslocamentos modificou-se significativamente. Antes havia uma grande concentração de locais de trabalho e estudo nas zonas centrais; hoje há uma grande dispersão.

O ônibus é, e continuará sendo por muito tempo, o principal - senão o único viável - meio de transporte público para a maioria da população de nossas cidades (NTU, jan/2009). Isto se deve, entre outros fatores, ao custo de aquisição, de investimentos para sua operação e a flexibilidade. Ônibus apresenta-se como único modo que, no curto prazo, pode favorecer o melhor equacionamento do problema da ineficiência da rede de transporte público urbano.

\subsection{Transporte Coletivo Urbano por ônibus no Estado do Rio de Janeiro}

No Rio de Janeiro, a participação de ônibus é expressiva e se associa ao próprio funcionamento da cidade (Figura 3). É gerenciado pela Secretaria Municipal de Transporte SMTR, órgão público também encarregado pela fiscalização do serviço fornecido pelas concessionárias de transporte no Rio de Janeiro. A melhoria de qualidade no funcionamento do transporte coletivo de passageiros é reflexo de um trabalho de planejamento estratégico para a política de transporte do setor (SMTR, 2009).

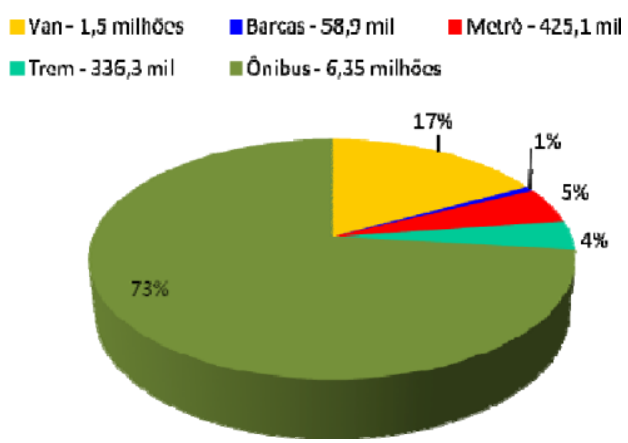

Figura 3 - Matriz de Transporte Público no Estado do Rio de Janeiro

Fonte: SMTR (2009) 
A estrutura do sistema de transporte da RMRJ não apresenta racionalidade, pois se caracteriza pela concorrência direta entre modos, esquema de integração bastante tênue; linhas de ônibus com itinerários longos e muitas vezes coincidentes com os sistemas sobre trilhos.

De acordo com Rio Ônibus, ao todo, são 47 empresas, operadas por agentes privados, com uma frota total de 7.256 carros, transportando, uma média mensal de 85.086.718 passageiros. Segundo o PDTU (2005), o sistema tem cerca de 1.500 linhas em operação na RMRJ; e considerando os dois sentidos de deslocamento, a extensão média das linhas é de 50,2 km e o tempo de ciclo médio gira em torno de 120 minutos. O conjunto de linhas na RMRJ oferece 200 mil viagens nos dias úteis - cerca de 1.497 viagens por linha - com a rodagem total de $4.280 .000 \mathrm{~km}$ por dia; ou seja, o Percurso Médio Mensal é de 8.000 km/por veículo.

\subsection{Discussão}

Ao todo, conseguiram-se repostas de cinco empresas, com a média de 49,4 anos de experiência operacional, 4,5 mil funcionários, detentoras de 1.650 veículos, 47,4\% dos quais com até 2 anos de idade, operam 169 linhas. Cabe destacar, entretanto, que estas empresas são braços de grupos bem maiores, remetendo, à priori, que suas estratégias de gestão traduzem diretrizes de seus grupos e que atual em áreas metropolitanas, como: baixada fluminense, capital do estado e litoral da RMRJ.

O questionário aplicado abrangeu as grandes áreas, a destacar: política e gestão de recursos humanos, Política e gestão da produção e operação, Estratégia de gestão da informação e tecnologia, Estratégia de gestão e avaliação de desempenho, Estratégia de gestão de custos e finanças, clientes. Cada uma destas grandes áreas foi detalhada em diversos aspectos relevantes e devidamente alinhada com os objetivos propostos. Além disso, os entrevistados também atribuíram valores, ao assinalarem em faixas previamente estabelecidos segundo a natureza das áreas. Isso permitiu que se pudesse dimensionar/mensurar os aspectos qualitativo da pesquisa.

Quanto à política e gestão de recursos humanos destacam-se: as empresas informaram que aplicam até $2 \%$ do seu faturamento anual em treinamento, proporcionando $22,3 \mathrm{~h}$ /ano/funcionário, com destaque para treinamentos de motoristas (70h/ano), cobradores (50h/ano) e administrativo (40h/ano). Empowerment, ciclo de palestras/treinamento com especialistas, incorporação de novas tecnologias e sistemas inteligentes e bônus convertidos em acréscimo salarial constituem principais meios usados para o incentivo à produtividade. Quanto a rotatividade da força de trabalho, em média, $31 \%$ têm mais de dez anos de empresa e outros $21 \%$ têm entre 5 à 10 anos da empresa. A escolaridade dominante é de primeiro grau, exceção dos gerentes que alcançam terceiro grau completo ou incompleto. A produção de transporte coletivo por ônibus é fortemente dominado por homens, embora a participação feminina vem crescendo, mas ainda situa-se entre $4,91 \%$ e 9,2\%. Na composição do quadro de pessoal, menos de $5 \%$ são portadores da alguma necessidade especial. Sobre a composição racial, a maioria é de pele de cor branca (63\%), seguindo-se os da cor preta (35\%). Os indígenas, asiáticos ou pardos são inexpressivos.

Quanto à política e gestão da produção e operação, a produção de TPU se dá na linha ou rede, posto que é perecível por excelência - não estocável, e cuja demanda é derivada. As empresas dimensionam a frota e a demanda de modo a minimizar custos - ociosidade dos equipamentos ou excesso de oferta. As empresas decidem suas produções e operações em função da demanda por linha/hora, cumprimento do contrato, já que se trata de um serviço público essencial e também pela concorrência, cujas médias são 37, 35 e 32 respectivamente. O denominador comum das decisões 
de produção das empresas é a concorrência (80\%) e a intensidade das dispersões obteve desvio padrão zero, figura 4 .

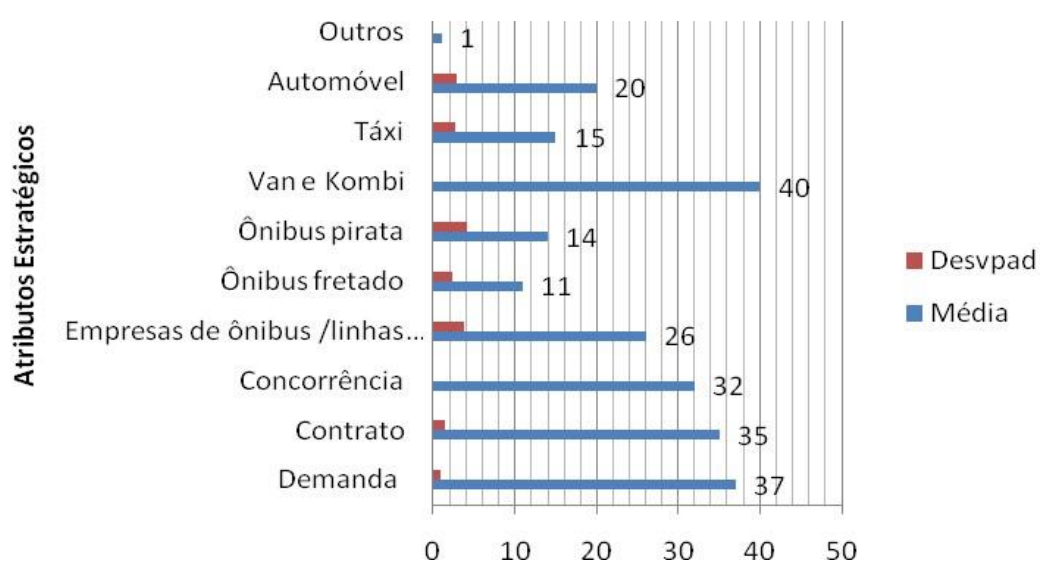

Figura 4 - Quesitos que afetam a decisão de produção/operação

Essa concorrência deveu-se mais ao crescimento de van e Kombi (100\%, na opinião dos gerentes das empresas) do que entre outras empresas de ônibus que compartilham linhas (sobreposição de trechos de linhas: média $=26$ e desvio-padrão $=3,70$ ). A maioria das empresas mede a produtividade por meio da relação Faturamento médio/mês, Faturamento por veículo/linha e Recita/km. Em relação aos seus fornecedores, $60 \%$ das empresas informaram que trabalham com o(s) mesmo(s) fornecedor(es) por mais de 5 anos e menos de 10 anos; e o restante $40 \%$ mantêm mesmos fornecedores há mais de 10 anos.

Quanto ao relacionamento com cliente - usuários - todas afirmam dispor de um serviço de atendimento ao cliente - SAC e que as reclamações dos mesmos são respondidas em $24 \mathrm{~h}$, em média. A interatividade com clientes tem se consolidado e contribuindo para melhorar resultados, segundo opinião de $83 \%$ dos gerentes de empresas pesquisadas; razão pela qual, em $50 \%$ dos casos, as empresas revelaram que não têm perdido clientes. A partir das reclamações de clientes, figura 5, as empresas procuram reagir e partir para política de fidelização,

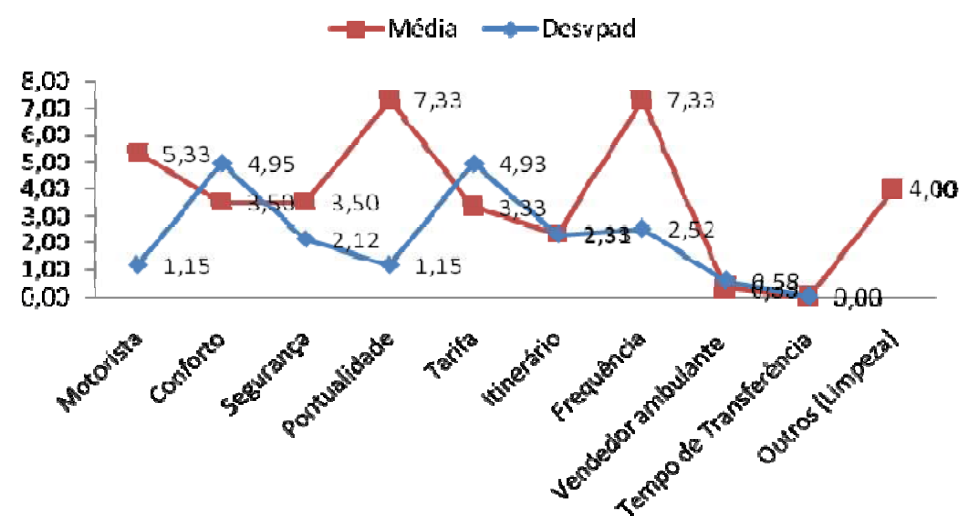

Figura 5 - Distribuição das reclamações de clientes 
Tendo como referencia o sua experiência vivencial, as empresas buscam se adequar, modelando os parâmetros conforto, segurança, tecnologia de transportes, etc, e buscando uma adequação da oferta, vide figura 6 .

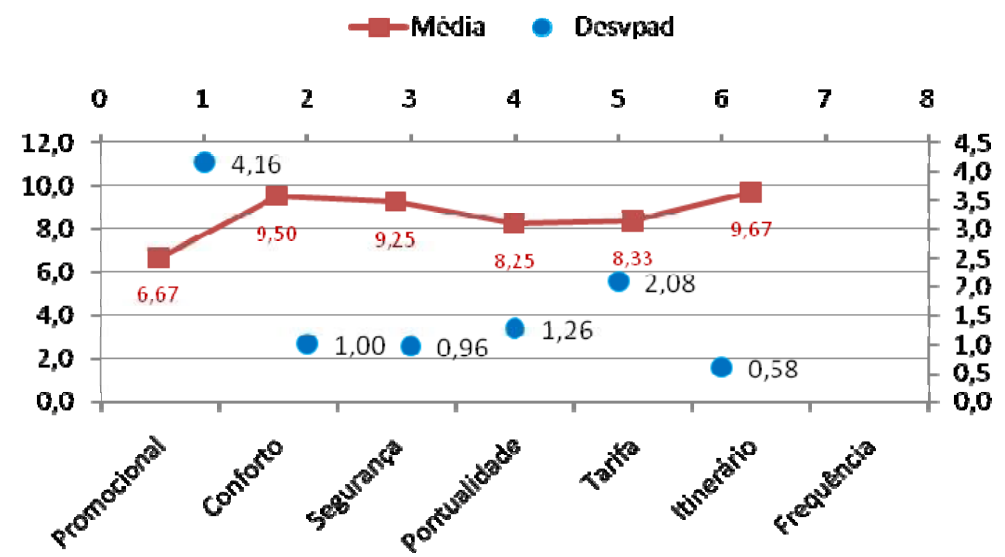

Figura 6- Distribuição das estratégias de fidelidade de clientes

Quanto a estratégia de gestão da informação e tecnologia, nenhuma das empresas possui veículos movidos com combustíveis renováveis. Entretanto, em todas já foram implantadas sistema de bilhetagem eletrônica. Em $80 \%$ das empresas, os funcionários usam rádio ou viva voz para agilizar a comunicação, principalmente, com seus inspetores. Em $80 \%$ das empresas já se utiliza câmera de filmagem no circuito interno dos ônibus. Essa combinação de ações tem reduzido eventos como assaltos, aumentado a sensação de segurança e melhorado a postura dos agentes rodoviários.

Quanto a estratégia gestão e avaliação de desempenho, apenas $20 \%$ das empresas pesquisadas revelaram conhecer métodos, como ABC, Gestão por metas, Balanced Scorecard, ERP e Endomarketing, mas não ficou clara se faz aplicação. Isso mostra que há carência nas ferramentas de avaliação de desempenho no negócio de TPU por ônibus, por isso, não conseguem responder se são ou não eficientes.

Quanto à estratégia de gestão de custos e finanças, as informações relacionadas às finanças indicam que, nos três últimos anos, nenhuma firma teve seu faturamento diminuído, tendo sido informado que em 50\% delas houve aumento. Nenhuma das firmas possui ações na Bolsa de Valores, e muito menos programas de incentivos aos empregados a comprar ações. No que tangem aos custos, os relacionados aos empregados consistem dos benéficos atribuídos, tipo ticket alimentação, refeição local, estacionamento, eventos motivacionais, planos de saúde, funeral, cesta básica, vale transporte, plano odontológico, assistência médica, convênio com farmácia e ótica. Todas as empresas recorrem ao mercado de trabalho para obter informações que orientam as práticas de remuneração, e os centros de custos estão bastante variáveis.

\section{CONCLUSÃO}

No Brasil, a eficácia da mobilidade urbana "sustentável" está fortemente relacionada à capacidade organizacional e de gestão das empresas de TPU por ônibus. Estas empresas, no curto prazo, possuem maior poder de flexibilidade de arranjos produtivos e de recursos compatíveis com as demandas, guardadas as restrições regulamentares e regulatórias impostas pelo poder público concedente. 
No Estado do Rio de Janeiro, 47 empresas privadas respondem, em média, por mais de 85 milhões viagens mensais. Na RMRJ, o conjunto de linhas em operação oferece um total de 200 mil viagens nos dias úteis - uma média de 1497 viagens por linha. Não obstante, vários estudos mostram que as empresas de ônibus, mesmo protegidas pela regulamentação, enfrentam grandes desafios, resultantes de: queda de demanda, longos percursos - em torno de 50,2 km; longo tempo de ciclo médio de produção - em torno de 120 minutos; forte concorrência inter e intra-modal; transportes alternativos (regulares e não regulares); crescimento da motorização, posto que uma parte de "clientes", principalmente a classe "C" migrara para transporte individual, dadas as facilidades de financiamento de veículos, o conforto, entre outros.

A maioria das empresas de ônibus percebeu mudanças e tendências do mercado "tardiamente", porque mesmo atuando no segmento de transportes, não dominava o comportamento do consumidor. Ou seja, os níveis de serviços estavam cada vez mais distantes das linhas de desejos e das necessidades dos usuários, cada vez mais exigentes. São bens do tipo diferenciado e especial, não passivos, individualizados, capazes de emitir juízos de valor na avaliação de benefício-custo, no desempenho, além de influenciar em todos os processos administrativos e de gestão de empresas de transportes.

Entretanto, outras empresas se modernizaram em termos de tecnologia de transportes e das práticas de gestão. Algumas dessas práticas evidenciam os aspectos que compõem o mix de marketing, principalmente, o foco no cliente, como condição de suas receitas; envolvendo iniciativas internas e externas das mesmas. Em transportes, significa que as operadoras que se despertaram para o novo contexto, tendiam a buscar maior compatibilidade entre todos os atributos característicos da prestação de serviço dessa natureza: a acessibilidade, a segurança, a disponibilidade, a regularidade, a confiabilidade, o conforto, a competência, a credibilidade, a cortesia, a empatia e a tangibilidade.

Em estudos de casos realizados, conseguiram-se respostadas de questionários aplicados junto a cinco empresas de ônibus do Estado do Estado do Rio de Janeiro, em que se procurou identificar principais práticas de gestão destas empresas para se manter e/ou crescer no mercado. As empresas eram maduras, com média de 49,4 anos de mercado, operando juntas 169 linhas e uma frota total de 1.650 veículos. O estudo constatou que as empresas praticam um mix de iniciativas gerenciais de sua produção, englobando empowerment, incorporação de novas tecnologias e sistemas inteligentes, ciclo de palestras/treinamento com especialistas, endomarketing, aplicação de até $2 \%$ do faturamento em treinamentos.

A perda de clientes indicado como um fenômeno decorrente, dentre outros, da mudança de padrões de deslocamento e do surgimento de novas centralidades, não afeta $50 \%$ das firmas entrevistadas. Ao contrário, elas assistem relativo aumento de usuários. A interatividade com clientes contribui, na acepção dos gestores das empresas, para melhorar seus resultados, na medida em que procuram atender e resolver os pontos críticos, objetos de maior intensidade das reclamações de usuários que são conforto, tarifas e itinerários.

As decisões de produção-operação das empresas são tomadas em função da demanda por linha/hora, cumprimento do contrato, sendo que em $80 \%$ das decisões, a concorrência prevalece. A relação com os fornecedores são geralmente duradoura, superando os 10 anos em $40 \%$ dos casos. A frequencia do monitoramento do clima organizacional varia de firma para firma, havendo as que o fazem anualmente, trimestralmente e até mensalmente. Neste último caso, a empresa diz aplicar o Programa 5S. A busca pela melhoria da eficiência é feita por meio de investimento na formação de novas lideranças, capazes de atender aos desafios internos e externos. 
Em termos tecnológicos, além da renovação de parte da frota, foi citada bilhetagem eletrônica, uso de rádio ou viva voz para comunicar entre funcionários e câmera de filmagem no circuito interno dos ônibus. Essas empresas medem sua produtividade por meio do Faturamento médio/mês, Faturamento por veículo/linha e Recita/km. Com efeito, por conta dessas iniciativas, as empresas informaram que, nos últimos três anos, os seus faturamentos aumentaram. A rigor, atendendo as peculiaridades da localidade onde atual, as empresas adotam práticas criativas de gestão para enfrentar a concorrência, mas ainda não evoluíram em métodos de avaliação de seus desempenhos.

\section{REFERENCIAS}

AMERICAN MARKETING ASSOCIATION - AMA. The American Marketing Association Releases New Definition for Marketing. Chicago - USA. 2008.

ASSOCIAÇÃO NACIONAL DE EMPRESAS DE TRANSPORTES URBANOS - NTU. Desoneração dos Custos das Tarifas do Transporte Público Urbano e Característica Urbana. Acessado em 01/2014. Em

<www.ntu.org.br/novosite/arquivos/DesoneracaoCustosTarifasAbr2009.pdf>

ASSOCIAÇÃO NACIONAL DE EMPRESAS DE TRANSPORTES URBANOS - NTU (2007). Perfil das Empresas Operadoras de Ônibus Urbanos do Brasil. Relatório Final da Pesquisa: Agosto de 2007. Brasília-DF, 24p.

ASSOCIAÇÃO NACIONAL DE EMPRESAS DE TRANSPORTES URBANOS - NTU (jan/2008).

Desempenho e qualidade nos sistemas de ônibus urbanos. 44 p. http://www.ntu.org.br

BAUER, Ruben . Gestão da Mudança: caos e complexidade nas organizações. São Paulo: Atlas. 1999.

BAUMAN, Zygmunt. Globalização: as conseqüências humanas. Rio de Janeiro: Jorge Zahar Editora. 1999.

BODMER, Milena. Gerenciamento de transportes coletivos: manual para o empresário. $1^{\text {a }}$ Edição. Rio de Janeiro: Fetranspor, 1992, 161p.

CECCONELlO, A.R. e AJZENTAL, A. A construção do plano de negócios: percurso metodológico para caracterização da oportunidade, estruturação, analise de viabilidade. São Paulo: Saraiva, 2008, 300p.

COSTA et al. A Gestão Empresarial Influenciando o Desenvolvimento das Empresas: uma análise no rio grande do norte. Anais... II Congresso de Pesquisa e Inovação da Rede Norte Nordeste de Educação Tecnológica. João Pessoa PB, 2007.

CUNHA, A. G.; e BODMER, M. Potencial de Retenção de Usuários de uma Empresa de Transporte. Dissertação de Mestrado. Rio de Janeiro: PET/COPPE/UFRJ, 275p. 2003.

DRUCKER, Peter Ferdinand. A Administração na Próxima Sociedade. São Paulo: Nobel, 2002

FERREIRA, A. A.; Reis, A. C. F.; Pereira, M. I. Gestão empresarial: de Taylor aos nossos dias. Evolução e tendências da moderna administração de empresas. São Paulo: Pioneira, 1997, 256p.

FERREIRA, E. A. características competitivas no mercado de transporte público urbano no Rio de Janeiro: o posicionamento dos novos entrantes. Rio de Janeiro: PET-UFRJ, 2006.

HENRY, E., \& Zioni, S. Ônibus na metrópole, articulações entre iniciativa privada e intervenção pública em são Paulo. Capítulo II. In. BRASILEIRO, A., Herny, E. \& Turma. Viação Ilimitada: ônibus das cidades brasileiras. São Paulo: Cultura Editores Associados, pp. 121-186. 2003.

KOTLER, Philip; KELLER, Kevin Lane. Administração de Marketing: a bíblia do marketing. Prentice Hall Brasil, 2006, $12^{\mathrm{a}}$ edição, 776p.

LEITE, M. de P. Reestruturação produtiva, novas tecnologias e novas formas de gestão da mão-de-obra. São Paulo, pp. 563 - 583, 1996.

MALAVÉ, C. \& BODMER. M. Mudança no foco gerencial das empresas de transporte. Anais... In: XII ANPET, 1998.

ORRICO FILHO, R. D.; BRASILEIRO, A.; SANTOS, E. M.; ARAGÃO J. J. \& Fortes J. A. A. Regulamentação do transporte público urbano por ônibus no brasil. Rio de Janeiro: COPPETEC/GEIPOT, 1996, 127p. 
PRAHALAD, C. K. \& RAMASWAMY, Venkat. O Futuro da Competição. Rio de Janeiro: Elsevier, 2004

PROCHNIK, V. Flexibilidade Espúria: Modernização Técnica com Desigualdade Social na Indústria Brasileira de Calçados. Anais... 19 Encontro Nac. de Economia. 1991, 3: 213-222.

SANTOS, M. P. S., et al. Análise da Relação entre o Sistema de Transporte e a Exclusão Social na Cidade do Rio de Janeiro. Rio de Janeiro: ENGEVISTA, v. 6, n. 3, p. 36-53. 2004.

SOUZA, B.B.P., GOSLING, M.M., GONÇALVES, C.A. Mensuração do mix de marketing de serviços, da satisfação e da lealdade em clientes de um banco de varejo. Revista Brasileira de Marketing - REMark, São Paulo, v. 12, n. 2, p. 108-132, abr./jun. 2013.

VIOTTI, E.B. Inserção de Ciência, Tecnologia e Inovação no Desenvolvimento Brasileiro. $3^{\text {a }}$ Conferência Nacional de Ciência, Tecnologia e Inovação. Brasília, 16 a 18 de novembro de 2005.

ZEITHAML, V.A.; BITNER, M.J. Marketing de Serviços: a empresa com foco no cliente. $2^{\mathrm{a}}$ ed. Porto Alegre: Bookman, 2003.

Versão preliminar deste artigo foi apresentada no VIII Rio de Transportes. 